\title{
Right-Sided Location Not Associated with Missed Colorectal Adenomas in an Individual-Level Reanalysis of Tandem Colonoscopy Studies
}

\author{
Katharina Zimmermann-Fraedrich ${ }^{1}$, Susanne Sehner ${ }^{2}$, Douglas K Rex ${ }^{3}$, Tonya Kaltenbach ${ }^{4}$, \\ Roy Soetniko ${ }^{4}$, Michael Wallace ${ }^{5}$, Wai K Leung ${ }^{6}$, Chuanguo Guo ${ }^{6}$, lan M. Gralnek ${ }^{7}$, \\ Eelco C. Brand ${ }^{8}$, Stefan Groth ${ }^{1}$, Guido Schachschal ${ }^{1}$, Hiroaki Ikematsu ${ }^{9}$, Peter D. Siersema ${ }^{10}$, \\ and Thomas Rösch ${ }^{1}$ \\ ${ }^{1}$ Department of Interdisciplinary Endoscopy, and ${ }^{2}$ Department of Medical Biometry and \\ Epidemiology, University Hospital Hamburg-Eppendorf, Hamburg, Germany, \\ ${ }^{3}$ Division of Gastroenterology and Hepatology, Indiana University School of Medicine, \\ Indianapolis, Indiana, United States, \\ ${ }^{4}$ Veterans Administration San Francisco and University of California San Francisco, San \\ Francisco, California, USA, \\ ${ }^{5}$ Division of and Hepatology, Mayo Clinic Jacksonville, Florida, Unites States, \\ ${ }^{6}$ Department of Medicine, Queen Mary Hospital, University of Hong Kong, Hong Kong, China, \\ ${ }^{7}$ Institute of Gastroenterology and Hepatology, Emek Medical Center, Afula, Israel, \\ ${ }^{8}$ Department of Gastroenterology and Hepatology, University Medical Center, Utrecht, the \\ Netherlands \\ ${ }^{9}$ Department of Gastroenterology and Gastrointestinal Oncology, National Cancer Center \\ Hospital East, Kashiwa, Chiba, Japan \\ ${ }^{10}$ Department of Gastroenterology and Hepatology, Radboud University Medical Center, \\ Nijmegen, the Netherlands
}

Corresponding author: Prof. Thomas Rösch MD, Department of Interdisciplinary Endoscopy, University Hospital Hamburg Eppendorf, Martinistr. 52, 20246 Hamburg, Germany. Email: t.roesch@uke.de

Contribution of Authors: Original data were received from all participating groups and were homogenized by two of the authors (KZF, TR) with feedback from all other coauthors from the different working groups for certain details. Data analysis was done by KZF and SS with support from TR, SG and GS. Manuscript writing was one by TR with input from all co-authors. All authors had access to the study data and had reviewed and approved the final manuscript

Conflict of Interest and Funding: There is no conflict of interest for any of the authors; the analysis was not funded.

This is the author's manuscript of the article published in final edited form as:

Zimmermann-Fraedrich, K., Sehner, S., Rex, D. K., Kaltenbach, T., Soetniko, R., Wallace, M., ... Rösch, T. (2019).

Right-Sided Location Not Associated with Missed Colorectal Adenomas in an Individual-Level Reanalysis of Tandem Colonoscopy Studies. Gastroenterology. https://doi.org/10.1053/j.gastro.2019.05.011 


\section{ABSTRACT}

Background \& Aims: Interval cancers occur more frequently in the right colon. One reason could be that right-sided adenomas are frequently missed in colonoscopy examinations. We reanalyzed data from tandem colonoscopies to assess adenoma miss rates in relation to location and other factors.

Methods: We pooled data from 8 randomized tandem trials, comprising 2218 patients who underwent diagnostic or screening colonoscopies (adenomas detected in $49.8 \%$ of subjects). We performed a mixed effects logistic regression with patients as cluster effects with different independent parameters. Factors analyzed included location (left vs right, splenic flexure as cut-off), adenoma size, form, and histologic features. Analyses were controlled for potential confounding factors such as patient sex and age, colonoscopy indication, and bowel cleanliness.

Results: Right-side location was not an independent risk factor for missed adenomas (odds ratio [OR] compared with the left side, $0.94 ; 95 \% \mathrm{Cl}, 0.75-1.17$ ). However, compared with adenomas $\leq 5 \mathrm{~mm}$, the OR for missing adenomas $6-9 \mathrm{~mm}$ was $0.62(95 \% \mathrm{Cl}, 0.44-0.87)$ and the OR for missing adenomas $\geq 10 \mathrm{~mm}$ was 0.51 (95\% Cl, 0.33-0.77). Compared with pedunculated adenomas, sessile (OR, 1.82; $95 \% \mathrm{Cl}, 1.16-2.85)$ and flat adenomas (OR, 2.47; $95 \% \mathrm{Cl}, 1.49-4.10)$ were more likely to be missed. Histologic features were not significant risk factors for missed adenomas (OR for adenomas with high-grade intraepithelial neoplasia, $0.68 ; 95 \% \mathrm{Cl}, 0.34-1.37$ and $\mathrm{OR}$ for sessile serrated adenomas, $0.87 ; 95 \% \mathrm{Cl}, 0.47-$ 1.64 compared with low-grade adenomas). Men had a higher number of adenomas per colonoscopy $(1.27 ; 95 \% \mathrm{Cl}, 1.21-1.33)$ than women $(0.86 ; 95 \% \mathrm{Cl}, 0.80-0.93)$. Men were less likely to have missed adenomas than women (OR for missed adenomas in men, $0.73 ; 95 \% \mathrm{Cl}$, 0.57-0.94).

Conclusions: In an analysis of data from 8 randomized trials, we found that right-side location of an adenoma does not increase its odds for being missed during colonoscopy, but adenoma size and histologic features do increase risk. Further studies are needed to determine why adenomas are more frequently missed during colonoscopies in women than men.

KEY WORDS: comparison, colorectal cancer, detection, endoscopy 


\section{Right-Sided Location and Miss Rates for Colorectal Adenomas - Reanalysis of Tandem Colonoscopy Studies}

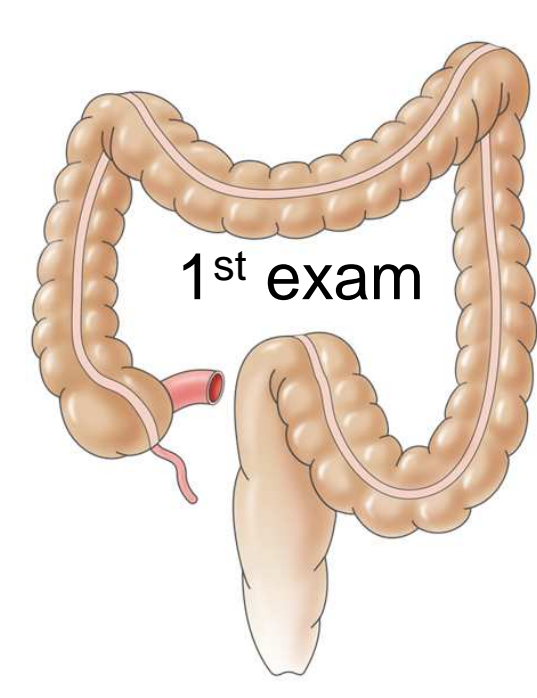

\section{Risk factors for missing adenomas}

- NOT right sided location (odds ratio, 0.94 for right vs left)

- NOT histology (high grade intraepithelial neoplasia, serrated adenoma)

- Adenoma size:

Odds ratio, 1.61 for diminutive $(\leq 5 \mathrm{~mm})$ vs small $(6-9 \mathrm{~mm})$ Odds ratio, 1.96 for diminutive $(\leq 5 \mathrm{~mm})$ vs large $(\geq 10 \mathrm{~mm})$

- Adenoma form:

Odds ratio, 2.47 for flat vs pedunculated

- Female sex

Odds ratio, 1.37 for women vs men

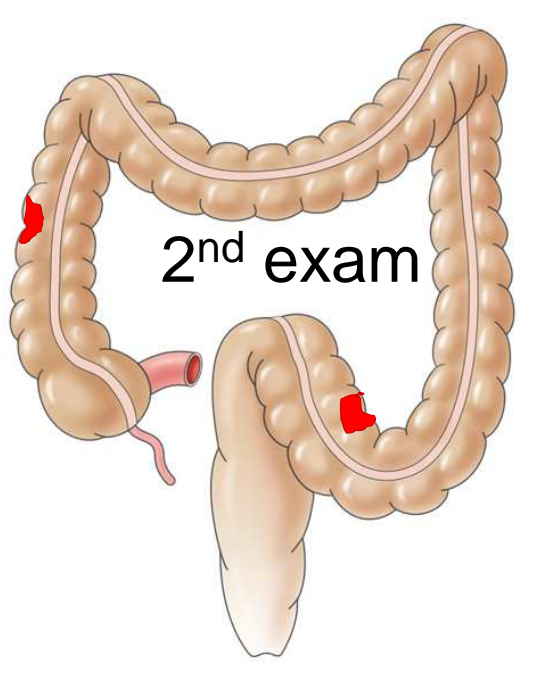

Gastroenterology 
The advantage of colonoscopy in reducing colorectal cancer (CRC) incidence and outcome is to find early cancer but also detect and remove adenomas as precursor lesions. However, the protective effect of colonoscopy achieves much less than a $100 \%$ CRC reduction $^{1-3}$, and various factors may be held responsible ${ }^{4-6}$ : These may be either a different lesion type and biology or a miss rate of specific lesions by colonoscopy. Both can lead to so-called interval cancers, defined as colorectal adenocarcinomas that are diagnosed between the time of the screening colonoscopy, and the scheduled time of surveillance colonoscopy ${ }^{7}$. Histologic analyses of such interval cancers have suggested that features related to the serrated pathway are more frequently found ${ }^{8-10}$, and it could be that serrated precursor lesions such as sessile serrated adenomas/polyps (SSP) which are usually flat, may also be more frequently missed. In addition, incomplete polyp resection, especially in larger ${ }^{11}$, but also in smaller lesions ${ }^{12}$ may a third factor. So, finally, lesion biology, miss rate and incomplete resection may come together to explain interval cancers.

In addition it has been repeatedly shown in previous publications using large databases, that interval cancers occur more frequently in the right colon ${ }^{6,13-17}$. Again, the same factors as mentioned above could account for the higher rate of right-sided interval cancers, either a different aggressiveness of (precursor) lesions or a higher miss rate on the right colonic side by colonoscopy. Concerning the first factor, we have recently shown from an analysis of the large German screening colonoscopy database, that risk adenomas (using the surrogate parameter of high-grade intraepithelial neoplasia) as well as flat adenomas (as opposed to non-flat lesions) are not more frequent in the right colon ${ }^{18}$, suggesting that lesion "biology" may not different in the right colon.

The other explanation is that adenomas as precursor lesions are more frequently missed in the right colon, due to a certain failure rate to reach the cecum and/or decreased bowel cleanliness in the right colon. Published evidence so far is limited and conflicting; a reanalysis of a randomized tandem study concluded from 406 patients that right-sided lesions were less frequently missed than left sided ones ${ }^{19}$, contradictory to another retrospective study in 659 patients undergoing two colonoscopies with a somewhat higher miss rate on the right side (for multiple polyps) ${ }^{20}$.

Therefore, the present study is based on the hypothesis, that there is a higher miss rate of adenomas in the right colon which could be a possible explanation for the higher rate of right-sided interval cancers. To test this hypothesis, we combined and reanalyzed original data from eight published randomized tandem trials ${ }^{21-28}$ which in their original publication examined various endoscopic techniques related to imaging and mechanical means (use of caps) to reduce adenoma miss rates (AMR). Adenomas found in the second of the tandem colonoscopies serve as gold standard for missed lesions; responsible factors are analyzed further in a multivariate analysis.

\section{Methods}

Authors of published randomized tandem colonoscopy studies were contacted after a careful PubMed search with the terms "colonoscopy" AND "tandem" (alternatively "back to back", "same day") OR "miss/missed/miss rate/additional adenoma" (alternatively) AND 
"randomized". The search was done in early 2015 covering the period after introduction of HD endoscopes in 2006, i.e. related to original papers published between 2007 and 2015. Only full text English language publications (randomized tandem trials) with 100 cases or more covering diagnostic or screening colonoscopy were to be included. Studies on special conditions (inflammatory bowel disease, polyposis syndromes, postoperative follow-ups) were excluded. Of 26 such studies shown as full text publication and in English language, which did not include special conditions such as IBD or Lynch syndrome, 15 had more than 100 patients and were real tandem studies (two full colonoscopies performed, and not limited to the right or left colon). Authors were contacted by mail several times, and seven groups finally agreed to send their data from a total of eight studies, with data transferred to excel files ${ }^{21-27}$. An own tandem study which finished patient recruitment in 2014 but was published later, was also included ${ }^{28}$. These were 4 single-center ${ }^{21-23,26}$ and 4 multicenter studies $24,25,27,28$. In addition, original data from another study were also received but tandem examinations were done only in the right colon ${ }^{29}$. Before final analysis, several feedback rounds with the authors were necessary to streamline the data and combine them into one database; these concerned different categorizations of adenoma size, forms and locations as well as histology definitions (e.g. for advanced adenoma). All authors had had access to the study data and had reviewed and approved the final manuscript.

Study performance characteristics: The methodological details of the included studies are shown in Table 1. The following categories were used for this combined analysis:

1. Indication for colonoscopy: screening, diagnostic, surveillance

2. Bowel cleanliness: (excellent, good, fair, poor)

3. Patient age and sex

4. Polyp size: $\mathrm{mm}$ categories (1-5mm, 6-9mm, $\geq 10 \mathrm{~mm}$ )

5. Polyp form: flat, sessile, pedunculated

6. Polyp location: left=distal (rectum, sigmoid and descending colon) versus right (transverse colon including flexures, if analysed separately, and ascending colon, cecum)

7. Histology: see below

Histopathology definitions and inclusion: Only lesions with histologic proof were included; thus, lesions in the database excluded from analysis which did not have histopathologic proof by polypectomy or at least biopsy. Hyperplastic polyps, adenomas with low- and highgrade intraepithelial neoplasia as well as (submucosally) invasive cancers were defined in the studies according to international standards ${ }^{30}$; central histopathology reading of all cases in one given study (if multicentric) was not available in any of the 4 multicentric studies. In only 6 of the 8 studies, sessile serrated adenomas/polyps (SSA/P) were defined as separate entity. Therefore, these 6 papers underwent the same analysis as described above for all 8 studies but with the additional parameter SSA/P as a risk factor for missing polyps.

Outcomes and definitions: Primary outcome was a missed adenoma. Missed adenomas were defined as those, not detected the first pass but by the second pass of the tandem examination which served as gold standard. AMR was calculated both on an adenoma basis (all missed adenomas/all patients) as well as on a patient basis (all patients with at least one adenoma missed). Only patients with polyps with adenomatous histology were considered. The primary predictorof interest was adenoma location. Secondary predictors of interest were other factors of possible influence on missed adenoma such as patient factors (sex, 
ACCEPTED MANUSCRTPT

age), indication for colonoscopy, colonoscopy factors (bowel cleanliness). These were analyzed with a multivariate analysis described in the following.

Statistics: Only patients with adenomas in one of the two passes were included in analysis who had a full dataset with regards to histology, size, form and location. Carcinomas (sm and more), hyperplastic polyps and other lesions were excluded (see Figure 1). Sample characteristics are given as absolute and relative frequencies or mean $+/$ - standard deviation, whichever is appropriate.

The prevalence of "adenomas not detected during the first pass" was analyzed using a mixed effects logistic regression because of every patient could have multiple detected adenomas a random intercept for the cluster patient was modeled. A random effect for the studies cannot be included because the effects of the combination of instruments and study cannot be separated, since one study includes one combination and some combinations are represented by one study only.

The combination of instruments, size, histology, form, location as well as all interactions of location with the other adenoma characteristics were considered as possible factors of influence and simultaneously included in the model (multivariate analysis). Moreover, the potential confounders gender, age, bowel preparation, total number of polyps within patient and indication were added to the model. In the case of an insignificant interaction term only the main effects were included, this decision was met by using the likelihood ratio test for model comparison. No further model selection methods were performed. Results are visualized by forest plots showing adjusted odds ratios (ORs) with corresponding 95\%Confidence intervals $(\mathrm{CI})$.

A two-tailed $p<0.05$ was considered to be statistically significant. Nominal $p$-values are reported without correction for multiplicity. Statistical analyses were computed using Stata 14.1 (STATA Corporation, College Station, Texas, USA).

\section{Results}

\section{Overview of study patients and lesions}

Of a total of 2218 patients included in the eight studies into this analysis, with one examiner performing the tandem examination in 6/8 studies (and two examiners in the remaining two). 1125 cases were excluded due to various reasons, mainly for absence of any polyps and cases with hyperplastic polyps only. Also, 7 cancer cases (i.e. tumors with submucosa invasion and beyond) had been excluded. Thus, 1093 patients with a total of 2401 adenomas were the basis of this analysis (see flow sheet in Figure 1). Patient and procedural data are shown in Table 2, overall results for adenomas found during both colonoscopy passes in Table 3. There was no correlation between adenoma shape and location $(p=0.482)$, so certain adenoma shapes were not more frequent in certain locations. Figure 2 shows the number of adenomas found during the first and second pass separately related to the number of patients. 
Results of the multivariate analysis with regards to patient- and adenoma-related miss rate factors are shown in Table 4 and Figure 3. All investigated interaction terms of adenoma characteristics with location (location by size, location by histology, location by form) showed no significant effects. Therefore in the final model only the main effects (location, size, histology and form) were included. Right-sided location was not found to be a risk factor for missing adenomas in these studies. To see whether there is a difference by histology or size that is still site-specific we additionally performed our described model by adding the interaction term of location and size and location and morphology and location and histology. There is no significant effect of the adenoma location for any adenoma characteristics (morphology by location $p=0.426$ / size by location $p=0.775 /$ histology by location $\mathrm{p}=0.210$ ).) Therefore a global side-independent effects of the patient characteristics can be assumed.

As expected, larger polyp size was independently associated with lower miss rates. Flat (OR 2.47; 95\%-Cl: 1.49,4.10) and sessile adenomas (OR 1.82; 95\%-Cl: 1.16,2.85) were more frequently missed than pedunculated polyps, and there was also a significant difference

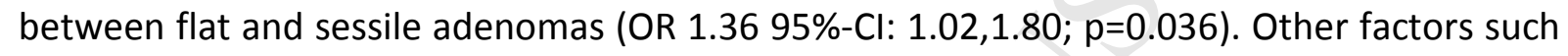
as adenoma histology and patient age were not significantly associated with the probability of being not detected in first exam.

Furthermore, another risk factor for AMR was female gender (OR 1.37; 95\%-Cl: 1.06,1.75, $\mathrm{p}=0.011$; for men OR 0.73; 95\%-Cl: 0.57,0.94, $\mathrm{p}=0.011$ ). As for adenoma occurrence in both sexes, the adenoma rate per colonoscopy (APC) was higher in men: APC was 1.27 (95\%-Cl: $1.21 ; 1.33)$ for males (1678 adenomas/1322 men) and 0.86 (95\%-Cl: 0.80;0.93) for females (754 adenomas/872 women).

Bowel preparation was not a risk factor in this analysis with the exception of borderline significance for the lowest grade/poor preparation (OR 1.92, 95\%-Cl: $1.00 ; 3.68, p=0.048$ ). If the grades were grouped differently, namely excellent/good and fair/poor together (as done in some of the papers included), results were not significant either (OR 1.25, 95\%-Cl: $0.90,1.74 ; p=0.182$ ).

As for histologic differentiation, results for SSA/P could only be analyzed from $6 / 8$ studies (2112/2395 adenomas) in which these lesions were separately categorized. The OR from these 6 studies for sessile serrated histology was $0.88(95 \%-\mathrm{Cl}: 0.45 ; 1.70)$ and not significant $(p=0.695)$, and this does not differ to the complete sample. Detailed results of these 6 studies are shown in Table 1 online and were similar for the other parameters analyzed as compared to the combined analysis of data from all 8 studies.

The influence of colonoscope characteristics on AMR which were the main topic of the respective studies, were included in the multivariate analysis but this aspect is shown separately in Table 2 online. As detailed in the individual studies, the method tested was mostly associated with a lower miss rate when performed first as compared to its use during the $2^{\text {nd }}$ pass. Furthermore we investigated a second starting model with above describe interaction terms as well all interaction terms between instrument and adenoma characteristics (instrument by location, instrument by histology, instrument by size and instrument by form). After a model selection with likelihood ratio test we found no 
significant interaction term, so the resulting model is always the model with the main effects only.

\section{Discussion}

Interval colorectal cancer (i-CRC) is the "negative" outcome parameter on the effectiveness of (screening) colonoscopy. Post-colonoscopy follow-up studies reported that even after a clear colon (following polypectomy of all detected lesions) the reduction of CRC incidence was much less than $100 \%{ }^{13,17}$. Thus, i-CRC can be considered as failure of colonoscopy to prevent CRC and has been shown to be associated with right sided location in a recent meta analysis $^{16}$. Also, recently, definitions and possible causes were summarized in a consensus statement ${ }^{7}$. As in previous analyses, assumptions are that about $50 \%$ of $\mathrm{i}-\mathrm{CRC}$ are due to missed lesions, and around $25 \%$ each due to either incomplete resection or de novo development ${ }^{4,6}$.

The striking side-difference between the left and right colon in the occurrence of i-CRC which was shown in post-colonoscopy follow-up studies ${ }^{13,14,17}$ as well as one meta analysis ${ }^{16}$ is one of several unsolved issues. Another recent review on i-CRC definitions summarized screening and combined (screening and diagnostic colonoscopy) studies in different tables ${ }^{31}$ : In this analysis, there was only a significant difference in the combined studies, while studies with screening colonoscopies only (much lower in total case number) had equal numbers of right- and left sided i-CRCs. The meaning of this possible difference between study types is unclear.

If this difference between right- and left sided interval cancers holds true for colonoscopy and also screening colonoscopy, it is not easy to explain. It could be due to a different biologic behavior of right-sided lesions or a higher miss rate or a combination of both. We recently showed from a very large database analysis of more than 5 million screening colonoscopies in the German National Screening database, that right-sided lesions did not have a higher rate of risk parameters such as high-grade intraepithelial neoplasia ${ }^{18}$. In the literature, results of "biology" of proximal versus distal adenomatous lesions provides only indirect evidence from analysis of primary lesions as well of post-resection recurrences which is somewhat controversial with regards to proximal lesions ${ }^{11,32-35}$.

Thus, it is likely that not biology, miss rate of lesions might be higher in the right colon to account for the higher rate of right-sided i-CRC. This may be due to a variety of factors such as failure to reach the cecum, reduced bowel cleanliness in the right colon, higher prevalence of right-sided flat lesions such as flat adenomas or sessile serrated adenomas/polyps (SSA/P). However, our reanalysis of original data from 8 studies did not confirm a higher proximal adenoma miss rate in a multivariate analysis. This confirmed results of a previous much smaller single-center study on 406 cases where miss rate was even higher in the left colon ${ }^{19}$. Our analysis is different from other meta analyses since we did not use published data from the respective papers as in a classical meta analysis, but combined original data from the randomized trials. Although we were dependent on authors, contributing their data, this type of analysis may be more precise. In fact, it took quite some efforts and enquiries with feedback from the authors to pool different size and histology categories as well as location. For example, the cut-off between left and right colon 
was quite inhomogeneous in the studies included in our trials, ranging from either two segments with the splenic flexure as cut-off to 3, 5 or 6 segments including the flexures as separate location ${ }^{21-28}$. These details are not obvious

Another possible limitation of our analysis is which studies were selected. Our selection was firstly based on our literature search included only fully published randomized trials in English language journals, true tandem studies (two full colonoscopies), studies with at least 100 cases, and those published after the introduction of HD colonoscopy after 2006. Secondly, of the 15 suitable studies we found between 2008 and 2015 under these selection criteria, we could obtain original data from only seven papers; as an $8^{\text {th }}$ study, we added data from a tandem study of our own group finished by that time. This selection may be a limitation of the existing study, but we were dependent on the voluntary cooperation of other groups. In addition, no study has been done in a pure screening collective, so that primary adenoma detection rates were rather high, namely mostly between 35 and $50 \%$ (see Table 1). Furthermore, we only received data from studies testing a new technique in the tandem approach, which may possibly lead to examiner bias towards the new method, a bias which cannot be excluded. The only tandem study with the same technique used in both arms could not provide us with original data; as it seems from the paper, there was a higher miss rate only in the left colon when compared to the rectum as reference (OR 2.9), while transverse and right colon did not have increased miss rates, again pointing towards an increased miss rate in the left rather than the right $\operatorname{colon}^{36}$.

A further limitation of the present analysis is that we ended inclusion of studies after 2015 since detailed analysis, author feedback and data homogenization took some time. Another literature search done since 2015 until present revealed 55 citations, and after exclusion of reviews, meta-analyses, secondary studies summarizing previous papers, tandem studies on the entire colon (instead of only right sided tandem) and data available on location, 7 studies remain $^{37-43}$, which in an additional paper-based meta analysis done by one of us (GGC) did not a higher miss rate in the right colon, rather a trend of a higher miss rate on the left side (see Figure 1 online).

What can we conclude from our results? It has to said that, even if, under study conditions of a tandem colonoscopy, proximal location could not be identified as a risk factor, there may be other circumstances under different study conditions and/or in real life which nevertheless may lead to a higher proximal miss rate. A reanalysis of three polyp prevention trials found a higher rate of proximal adenomas after a (seemingly) clean colon, whereby recurrent and missed cancers may be difficult to differentiate ${ }^{44}$. Furthermore, the fact that the miss rate is monitored such as in a tandem study, may per se lead to a higher attentiveness of participating colonoscopists, so that the first pass may reveal higher primary ADR (and hence, lower AMR) than in daily life. Secondly, in supervised national screening programmes (self-reported) cecal intubation rates are usually over $90 \%$, such as shown in Germany $^{45}$, Austria ${ }^{46}$, Norway ${ }^{47}$, The Netherlands and $\mathrm{UK}^{48}$, with somewhat lower rates for France ${ }^{49}$, but in countries and areas with less rigorous quality and documentation programmes, cecal intubation rates may be substantially lower ${ }^{50-52}$. Furthermore, cecal rates always depend on self-reporting, without an easy independent gold standard. However, documentation quality of cecal reach may be limited ${ }^{53,54}$, the independent assessment of cecal photographs leads to variable results ${ }^{55-57}$, and comparisons with external imaging such as scope guide for cecal reach are not available; however, colonoscopic localization of lesions has been repeatedly shown to be inaccurate in nearly $20 \%$ of cases when compared to magnetic imaging (scope guide) and other controls such as 
CT or even surgery ${ }^{58,59}$; whether this could be extrapolated to a limited accuracy to define full cecal intubation, is likely, but finally unknown. In any case, we need more long-term follow-up studies from the various screening programmes on either primary screening colonoscopy or stool-based screening programmes to find out whether there is a clear predominance of right sided missed cancers.

The same may be true for bowel cleanliness; only in the category "poor" was there was a significantly higher miss rates, which confirms previous experience by our group ${ }^{60}$ and by others. For most studies on ADR and AMR as well as for large colonoscopy databases, the assessment bowel cleanliness again rests on self-reporting. However, there is evidence that bowel cleanliness is rated better by colonoscopists than by external validation (video assessment) by independent experts ${ }^{61,62}$. In addition, different scores and ratings have been used for all these studies and databases, so that comparability is limited, as can be seen by very different cleanliness scores, e.g. in the Austrian ${ }^{46}$ and British programme reports on $94 \%$ excellent/adequate cleansing rates ${ }^{48}$.

The assumption of a higher miss rate in right-sided adenomas in real life as compared to study conditions of our tandem analysis would also imply that missed lesions (and hence interval cancers) would increase in frequency from the mid colon to the cecum since the most distal parts the areas with assumed detection failures when the cecum is not reached and/or the ascending colon and cecum are the least clean parts. Unfortunately, only few studies reveal the precise location of interval cancers, but of 76 such cancers, $47 \%$ were located in cecum and ascending colon in a German screening study ${ }^{63}$, while in a Polish screening study with 42 interval cancers, only 7 were located in these segments ${ }^{64}$. In combined studies analyzing screening and diagnostic colonoscopies, the two largest showed either $43 \%$ of $874 \mathrm{i}$-CRC with known location in cecum or ascending colon (only $7 \%$ in transverse colon) $)^{65}$, or, as in the larger study, $31 \%$ in cecum, $29 \%$ in ascending colon including hepatic flexure in a total of $4104 \mathrm{i}-\mathrm{CRCs}^{66}$. In analogy, our own Exera III study including 856 patients, $37 \%$ of all missed adenomas were located in the cecum and ascending colon, $25 \%$ in the transverse colon and $48 \%$ in the left colon ${ }^{28}$.

A further issue is that serrated adenomas (SSA/P) were not missed more frequently per se in our analysis (however flat adenomas showed a higher miss rate than sessile or pedunculated ones). It could be that in the two studies, which did not have SSA/P as separate category, these lesions were counted among hyperplastic lesions. However, it is unlikely that histologic subdifferentiation in these two papers would have changed the results substantially, since results in the remaining 6 papers were clear with an OR of 0.87 and none of the other parameters analyzed was much different between the analysis of all 8 studies (see Table 4) and the 6 studies with SSA/P analyzed separately (see Table 1 online). In general, both endoscopic and histologic diagnosis of SSA/P are subject to substantial interobserver variability, at least in most studies ${ }^{67,68}$, which makes interpretation of most study results more difficult than for conventional adenomas.

In conclusion, in a careful tandem colonoscopy under study conditions, adenomas are not more frequently missed in the right colon. We do not know whether miss rate might be substantially higher in the right colon in real life colonoscopy or whether other factors account for the higher rate of interval cancers in the right colon. In all likelihood, it is not a higher miss rate for sessile serrated adenomas either, as we also could show. These results could also be interpreted in a way, that applying a higher scrutiny in the right colon than 
done in daily practice - as might be the case in tandem studies - could help to solve the problem of a higher rate of right-sided interval cancers and overall effects of colonoscopy. 


\section{FIGURE LEGENDS}

Figure 1: Flow sheet of patient and lesion inclusion in our analysis

Figure 2: Combined patient numbers with adenomas found during first and second pass

Figure 3: Risk factors for missing an adenoma in the multivariate analysis (see text) 


\section{References}

1. Brenner $\mathrm{H}$, Stock $\mathrm{C}$, Hoffmeister $\mathrm{M}$. Effect of screening sigmoidoscopy and screening colonoscopy on colorectal cancer incidence and mortality: systematic review and meta-analysis of randomised controlled trials and observational studies. Bmj 2014;348:g2467.

2. Lieberman D, Ladabaum U, Cruz-Correa M, et al. Screening for Colorectal Cancer and Evolving Issues for Physicians and Patients: A Review. Jama 2016;316:2135-2145.

3. Imperiale TF, Ransohoff DF. Screening for Colorectal Neoplasia. N Engl J Med 2017;376:1598-9.

4. Robertson DJ, Lieberman DA, Winawer SJ, et al. Colorectal cancers soon after colonoscopy: a pooled multicohort analysis. Gut 2014;63:949-56.

5. Dominitz JA, Robertson DJ. Interval cancers: learning from the past as we build for the future. Am J Gastroenterol 2013;108:1341-3.

6. Pohl H, Robertson DJ. Colorectal cancers detected after colonoscopy frequently result from missed lesions. Clin Gastroenterol Hepatol 2010;8:858-64.

7. Rutter MD, Beintaris I, Valori R, et al. World Endoscopy Organization Consensus Statements on Post-Colonoscopy and Post-Imaging Colorectal Cancer. Gastroenterology 2018;155:909-925.e3.

8. Nishihara R, Wu K, Lochhead P, et al. Long-term colorectal-cancer incidence and mortality after lower endoscopy. N Engl J Med 2013;369:1095-105.

9. Arain MA, Sawhney M, Sheikh S, et al. CIMP status of interval colon cancers: another piece to the puzzle. Am J Gastroenterol 2010;105:1189-95.

10. Stoffel EM, Erichsen R, Froslev T, et al. Clinical and Molecular Characteristics of PostColonoscopy Colorectal Cancer: A Population-based Study. Gastroenterology 2016;151:870878.e3.

11. Moss A, Williams SJ, Hourigan LF, et al. Long-term adenoma recurrence following wide-field endoscopic mucosal resection (WF-EMR) for advanced colonic mucosal neoplasia is infrequent: results and risk factors in 1000 cases from the Australian Colonic EMR (ACE) study. Gut 2015;64:57-65.

12. Pohl H, Srivastava A, Bensen SP, et al. Incomplete polyp resection during colonoscopy-results of the complete adenoma resection (CARE) study. Gastroenterology 2013;144:74-80.e1.

13. Baxter NN, Goldwasser MA, Paszat LF, et al. Association of colonoscopy and death from colorectal cancer. Ann Intern Med 2009;150:1-8.

14. Brenner $\mathrm{H}$, Chang-Claude J, Seiler $\mathrm{CM}$, et al. Protection from colorectal cancer after colonoscopy: a population-based, case-control study. Ann Intern Med 2011;154:22-30.

15. Martinez ME, Baron JA, Lieberman DA, et al. A pooled analysis of advanced colorectal neoplasia diagnoses after colonoscopic polypectomy. Gastroenterology 2009;136:832-41.

16. Singh S, Singh PP, Murad MH, et al. Prevalence, Risk Factors, and Outcomes of Interval Colorectal Cancers: A Systematic Review and Meta-Analysis. Am J Gastroenterol 2014.

17. Brenner $\mathrm{H}$, Hoffmeister $\mathrm{M}$, Arndt $\mathrm{V}$, et al. Protection from right- and left-sided colorectal neoplasms after colonoscopy: population-based study. J Natl Cancer Inst 2010;102:89-95.

18. Rosch T, Altenhofen L, Kretschmann J, et al. Risk of Malignancy in Adenomas Detected During Screening Colonoscopy. Clin Gastroenterol Hepatol 2018;16:1754-1761.

19. Leufkens AM, van Oijen MG, Vleggaar FP, et al. Factors influencing the miss rate of polyps in a back-to-back colonoscopy study. Endoscopy 2012;44:470-5.

20. Lee J, Park SW, Kim YS, et al. Risk factors of missed colorectal lesions after colonoscopy. Medicine (Baltimore) 2017;96:e7468.

21. Kaltenbach T, Friedland S, Soetikno R. A randomised tandem colonoscopy trial of narrow band imaging versus white light examination to compare neoplasia miss rates. Gut 2008;57:1406-12.

22. Hewett DG, Rex DK. Cap-fitted colonoscopy: a randomized, tandem colonoscopy study of adenoma miss rates. Gastrointest Endosc 2010;72:775-81.

23. Gross SA, Buchner AM, Crook JE, et al. A comparison of high definition-image enhanced colonoscopy and standard white-light colonoscopy for colorectal polyp detection. Endoscopy 2011;43:1045-51.

24. Leufkens AM, DeMarco DC, Rastogi A, et al. Effect of a retrograde-viewing device on adenoma detection rate during colonoscopy: the TERRACE study. Gastrointest Endosc 2011;73:480-9. 
25. Gralnek IM, Siersema PD, Halpern Z, et al. Standard forward-viewing colonoscopy versus fullspectrum endoscopy: an international, multicentre, randomised, tandem colonoscopy trial. Lancet Oncol 2014;15:353-60.

26. Leung WK, Lo OS, Liu KS, et al. Detection of colorectal adenoma by narrow band imaging (HQ190) vs. high-definition white light colonoscopy: a randomized controlled trial. Am J Gastroenterol 2014;109:855-63.

27. Dik VK, Gralnek IM, Segol O, et al. Multicenter, randomized, tandem evaluation of EndoRings colonoscopy--results of the CLEVER study. Endoscopy 2015;47:1151-8.

28. Pioche M, Denis A, Allescher HD, et al. Impact of 2 generational improvements in colonoscopes on adenoma miss rates: results of a prospective randomized multicenter tandem study. Gastrointest Endosc 2018;88:107-116.

29. Ikematsu $H$, Saito $Y$, Tanaka $S$, et al. The impact of narrow band imaging for colon polyp detection: a multicenter randomized controlled trial by tandem colonoscopy. J Gastroenterol 2012;47:1099-107.

30. Bosman FT, Carneiro, F., Hruban, R.H., Theise, N.D. WHO Classification of Tumours of the Digestive System. International Agency for Research on Cancer 2010;3.

31. Sanduleanu S, le Clercq CM, Dekker E, et al. Definition and taxonomy of interval colorectal cancers: a proposal for standardising nomenclature. Gut 2015;64:1257-67.

32. Gupta S, Balasubramanian BA, Fu T, et al. Polyps with advanced neoplasia are smaller in the right than in the left colon: implications for colorectal cancer screening. Clin Gastroenterol Hepatol 2012;10:1395-1401.e2.

33. Loberg $\mathrm{M}$, Kalager $\mathrm{M}$, Holme $\mathrm{O}$, et al. Long-term colorectal-cancer mortality after adenoma removal. N Engl J Med 2014;371:799-807.

34. Oka S, Tanaka S, Saito $\mathrm{Y}$, et al. Local recurrence after endoscopic resection for large colorectal neoplasia: a multicenter prospective study in Japan. Am J Gastroenterol 2015;110:697-707.

35. Sawhney MS, Dickstein J, LeClair J, et al. Adenomas with high grade dysplasia and early adenocarcinoma are more likely to be sessile in the proximal colon. Colorectal Dis 2015.

36. Heresbach D, Barrioz T, Lapalus MG, et al. Miss rate for colorectal neoplastic polyps: a prospective multicenter study of back-to-back video colonoscopies. Endoscopy 2008;40:284-90.

37. Gilani N, Stipho S, Panetta JD, et al. Polyp detection rates using magnification with narrow band imaging and white light. World J Gastrointest Endosc 2015;7:555-62.

38. Halpern Z, Gross SA, Gralnek IM, et al. Comparison of adenoma detection and miss rates between a novel balloon colonoscope and standard colonoscopy: a randomized tandem study. Endoscopy 2015;47:301.

39. Kumar S, Thosani N, Ladabaum U, et al. Adenoma miss rates associated with a 3-minute versus 6-minute colonoscopy withdrawal time: a prospective, randomized trial. Gastrointest Endosc 2017;85:1273-1280.

40. Papanikolaou IS, Apostolopoulos P, Tziatzios G, et al. Lower adenoma miss rate with FUSE vs. conventional colonoscopy with proximal retroflexion: a randomized back-to-back trial. Endoscopy 2017;49:468-475.

41. Triantafyllou K, Polymeros D, Apostolopoulos P, et al. Endocuff-assisted colonoscopy is associated with a lower adenoma miss rate: a multicenter randomized tandem study. Endoscopy 2017;49:1051-1060.

42. Anderson JC, Kahi CJ, Sullivan A, et al. Comparing adenoma and polyp miss rates for total underwater colonoscopy versus standard $\mathrm{CO} 2$ : a randomized controlled trial using a tandem colonoscopy approach. Gastrointest Endosc 2018.

43. Hassan C, Senore C, Manes G, et al. Diagnostic Yield and Miss Rate of EndoRings in an Organized Colorectal Cancer Screening Program: the SMART (Study Methodology for ADR-Related Technology) Trial. Gastrointest Endosc 2018.

44. Pohl H, Robertson DJ, Mott LA, et al. Association between adenoma location and risk of recurrence. Gastrointest Endosc 2016;84:709-16.

45. Brenner $\mathrm{H}$, Altenhofen L, Kretschmann J, et al. Trends in Adenoma Detection Rates During the First 10 y of the German Screening Colonoscopy Program. Gastroenterology 2015. 
46. Waldmann E, Gessl I, Sallinger D, et al. Trends in quality of screening colonoscopy in Austria. Endoscopy 2016;48:1102-1109.

47. Moritz V, Holme O, Leblanc M, et al. An explorative study from the Norwegian Quality Register Gastronet comparing self-estimated versus registered quality in colonoscopy performance. Endosc Int Open 2016;4:E326-32.

48. Lee TJ, Rees CJ, Blanks RG, et al. Colonoscopic factors associated with adenoma detection in a national colorectal cancer screening program. Endoscopy 2014;46:203-11.

49. Leuraud K, Jezewski-Serra D, Viguier J, et al. Colorectal cancer screening by guaiac faecal occult blood test in France: Evaluation of the programme two years after launching. Cancer Epidemiol 2013;37:959-67.

50. Evans DV, Cole AM, Norris TE. Colonoscopy in rural communities: a systematic review of the frequency and quality. Rural Remote Health 2015;15:3057.

51. Kaz AM, Dominitz JA. Editorial: The Name Game: Circumventing Quality Metrics by Categorizing Incomplete Colonoscopy as Sigmoidoscopy. Am J Gastroenterol 2017;112:1553-1555.

52. Beg S, Sansone S, Manguso F, et al. The Conversion of Planned Colonoscopy to Sigmoidoscopy and the Effect of this Practice on the Measurement of Quality Indicators. Am J Gastroenterol 2017;112:1545-1552.

53. Coe SG, Panjala C, Heckman MG, et al. Quality in colonoscopy reporting: an assessment of compliance and performance improvement. Dig Liver Dis 2012;44:660-4.

54. Palmer LB, Abbott DH, Hamilton N, et al. Quality of colonoscopy reporting in community practice. Gastrointest Endosc 2010;72:321-7, 327.e1.

55. Powell $\mathrm{N}$, Knight $\mathrm{H}$, Dunn J, et al. Images of the terminal ileum are more convincing than cecal images for verifying the extent of colonoscopy. Endoscopy 2011;43:196-201.

56. Rex DK. Still photography versus videotaping for documentation of cecal intubation: a prospective study. Gastrointest Endosc 2000;51:451-9.

57. Thuraisingam Al, Brown JL, Anderson JT. What are the sensitivity and specificity of endoscopic photographs in determining completion of colonoscopy? Results from an online questionnaire. Eur J Gastroenterol Hepatol 2008;20:567-71.

58. Moug SJ, Fountas S, Johnstone MS, et al. Analysis of lesion localisation at colonoscopy: outcomes from a multi-centre U.K. study. Surg Endosc 2017;31:2959-2967.

59. Johnstone MS, Moug SJ. The accuracy of colonoscopic localisation of colorectal tumours: a prospective, multi-centred observational study. Scott Med J 2014;59:85-90.

60. Adler A, Wegscheider K, Lieberman D, et al. Factors determining the quality of screening colonoscopy: a prospective study on adenoma detection rates, from 12,134 examinations (Berlin colonoscopy project 3, BECOP-3). Gut 2013;62:236-41.

61. Ell C, Fischbach W, Bronisch HJ, et al. Randomized trial of low-volume PEG solution versus standard PEG + electrolytes for bowel cleansing before colonoscopy. Am J Gastroenterol 2008;103:883-93.

62. C E. Personal communication on Ell C et al. Am J Gastroenterol 2008 Apr;103(4):883-93.

63. Brenner $\mathrm{H}$, Chang-Claude J, Seiler $\mathrm{CM}$, et al. Interval cancers after negative colonoscopy: population-based case-control study. Gut 2012;61:1576-82.

64. Kaminski MF, Regula J, Kraszewska E, et al. Quality indicators for colonoscopy and the risk of interval cancer. N Engl J Med 2010;362:1795-803.

65. Erichsen R, Baron JA, Stoffel EM, et al. Characteristics and survival of interval and sporadic colorectal cancer patients: a nationwide population-based cohort study. Am J Gastroenterol 2013;108:1332-40.

66. Cooper GS, Xu F, Barnholtz Sloan JS, et al. Prevalence and predictors of interval colorectal cancers in medicare beneficiaries. Cancer 2012;118:3044-52.

67. Okamoto K, Kitamura S, Kimura T, et al. Clinicopathological characteristics of serrated polyps as precursors to colorectal cancer: Current status and management. J Gastroenterol Hepatol 2017;32:358-367.

68. O'Connell BM, Crockett SD. The clinical impact of serrated colorectal polyps. Clin Epidemiol 2017;9:113-125. 


\section{TABLES}

Table 1: Characteristics of the included studies in order of paper publication year (methodology as described in the resp.paper)

\begin{tabular}{|c|c|c|c|c|c|c|c|c|c|}
\hline & & STUDY $1^{21}$ & STUDY $2^{22}$ & $S T U D Y 3^{23}$ & STUDY $4^{24}$ & STUDY $5^{26}$ & STUDY $6^{25}$ & $S T U D Y 7^{27}$ & STUDY $8^{28}$ \\
\hline \multicolumn{10}{|l|}{ GENERAL } \\
\hline No of patients & & 276 & 100 & 96 & 349 & 360 & 98 & 116 & 856 \\
\hline Study topic (new method) & & NBI & Cap & HDTV & Third Eye & NBI & FUSE & Endorings & 2 generational \\
\hline Study period (months) & & 13 & 35 & 23 & 12 & 12 & 14 & 12 & 22 \\
\hline \multicolumn{10}{|l|}{ METHODOLOGY } \\
\hline Indications (\%) & & SC,SV,D & SC,SV & SC,SV & SC,SV,D & SC,SV,D & SC,SV,D & SC,SV,D & SC; D \\
\hline No of centers in study & & 1 & 1 & 1 & 9 & 1 & 6 & 3 & 6 \\
\hline No of examiners in study & & 6 & 2 & 8 & 15 & 8 & 15 & 6 & several \\
\hline Experience (colonoscopy no) & & n.r. & n.r. & 5000 & long experience & $500-2000^{+}$ & n.r. & n.r. & 500 \\
\hline One/two examiners per pat. & & 1 & 1 & 2 & 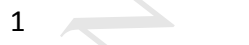 & 1 & 1 & 1 & 2 \\
\hline Bowel cleanliness score & BBPS & 3 grades & 5 grades & Ottawa s & 4 grades & Ottawa & BBPS & BBPS & \\
\hline Sedation used & & $M / F, P$ & $\mathrm{P}$ & $M+F / M P$ & n.r. & $\mathrm{M}, \mathrm{F}$ or $\mathrm{PE}$ & $M, F, P$ & $M / F, P$ & $M, P$ \\
\hline \multicolumn{10}{|l|}{ Examination times (min) } \\
\hline Overall times & & + & + & + & n.r. & n.r. & 14.5 vs $12.2^{\S}$ & 22 vs $18.5^{\S}$ & $\operatorname{diff}^{++++}$ \\
\hline Withdrawal & & + & + & + & n.r. & 9.9 vs 10.4 & 6.2 vs $5.62^{\S}$ & 7.4 vs 7.2 & $\operatorname{diff}^{++++}$ \\
\hline Histologic criteria* & & all & all & all + VC**all +VC & all & diff. gro & sping $^{++} \quad$ all & all & \\
\hline SSA separate category* & yes & no & yes & & yes & $?$ & yes & yes & \\
\hline Excluded lesions w/o histology & & no & no & no & no & no & no & no & no \\
\hline Polyp localization documented & & prox/distal (SF) & 6 segments & 8 segments & 8 segments & 3 segments & prox/distal (SF) & prox/distal (SF) & 6 segments \\
\hline Polyp size documented & & $\mathrm{mm}$ & $\mathrm{mm}$ & $\mathrm{mm}$ & $\mathrm{mm}$ & $\mathrm{mm}$ & 3 categories $^{+++}$ & $\mathrm{mm}$ & $\mathrm{mm}$ \\
\hline Polyp form documented & & ped/sess/flat & ped/sess/flat & no & ped/sess/flat & ped/sess/flat & ped/sess/flat & ped/sess/flat & Paris \\
\hline Case number calculation & & $15 \%$ vs $30 \%$ & AMR $15 \%$ vs $30 \%$ & AMR $20 \%$ vs $31 \%$ & n.r. & ADR $50 \%$ vs $35 \%$ & AMR $15 \%$ vs $35 \%$ & AMR $10 \%$ vs $35 \%$ & $10 \%$ vs $20 \%$ \\
\hline \multicolumn{10}{|l|}{ RESULTS } \\
\hline Overall ADR after 2 passes & & $49 \%$ & $49 \%$ & $44 \%$ & $46 \%$ & $61 \%$ & $63 \%$ & $57 \%$ & $52 \%$ \\
\hline a-AMR new vs control & & $15 \%$ vs $12 \%$ & $12.6 \%$ vs $12.1 \%$ & $27 \%$ vs $49 \%^{\S}$ & $21 \%$ vs $29 \%^{\S}$ & $22 \%$ vs $21 \%$ & $23 \%$ vs $62 \%^{\S}$ & $12 \%$ vs $47 \%^{\S}$ & $17 \%$ vs $30 \%^{\S}$ \\
\hline ADR first pass (new vs control) & & $50 \%$ vs $44 \%$ & $50 \%$ vs $44 \%$ & $25.5 \%$ vs $37 \%$ & n.r. & $48 \%$ vs $34 \%^{\S}$ & $34 \%$ vs $28 \%$ & $49 \%$ vs $29 \%^{\S}$ & $44 \%$ vs $36.5 \%^{\S}$ \\
\hline
\end{tabular}

$\S$ significant $(P<0.05)$. Abbreviations: n.r. not reported. Indication: SC screening, SV surveillance, D diagnostic. BBPS Boston Bowel Preparation Score. Sedation: M midazolam, F fentanyl, P propofol, MP meperidine, PE pethidine. ADR adenoma detection rate (patients with at least one adenoma/all patients), a-AMR adenoma miss rate on adenoma basis. SF splenic flexure as cut-off between proximal and distal

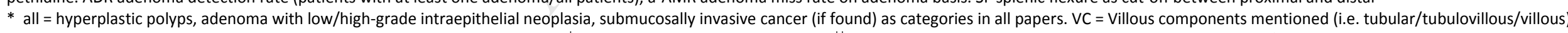

** in this paper tubulovillous was combined with HGIN adenoma in one group ${ }^{+} 500$ for fellows and 2000 for experts ${ }^{++} 3$ groups: LGIN, HGIN plus villous components, hyperplastic/normal tissue, no SSA menitoned.

${ }^{+++} 1-5 \mathrm{~mm}, 6-9 \mathrm{~mm}, \geq 100 \mathrm{~mm} .{ }^{+++}$net withdrawal and overall times significantly different between groups, but in different directions (see paper for details) ${ }^{2}$ 
Table 2: Combined study data (mean; range) on the 1093 study patients with colonoscopy performance characteristics

\begin{tabular}{llll}
\hline Patient data & & mean & range \\
\hline Sex & Female & $373(34,1 \%)$ & \\
& Male & $720(65,9 \%)$ & \pm 9.9 \\
Age & & 62.2 & \\
\hline Colonoscopy data & & \\
\hline \multirow{2}{*}{ Indication } & Screening & $335(30,6 \%)$ & \\
& Surveillance & $380(34,8 \%)$ \\
& Diagnostic & $373(34,1 \%)$ \\
& Missing/unknown/other & $5(0,5 \%)$ \\
Bowel cleanliness & Excellent & $369(33,8 \%)$ \\
& Good & $547(50,0 \%)$ \\
& Fair & $140(12,8 \%)$ & \\
& Poor & $37(3,4 \%)$
\end{tabular}


Table 3: Combined study data (mean; range) on detected and missed polyps/adenomas in the study patients during both passes of tandem colonoscopy; for patient numbers and inclusion/exclusion see Figure 1 , for additional adenomas found during the second pass, see Figure $2^{* *}$

\section{Patient basis ( $\mathrm{N}=2194$ patients. ${ }^{*}$ )}

\section{Adenoma detection rate}

ADR (\% of patient with at least one adenoma)

Overall (both passes)

$1^{\text {st }}$ pass

$2^{\text {nd }}$ pass

Mean no of adenomas/adenoma carrier (overall)
49.8\% (1093 adenomas/2194 patients)

$\mathrm{n}=908$ with at least one adenoma

$\mathrm{n}=447$ with at least one (more) adenoma**

$2.19(2401 / 1093)$

\section{Subgroup detection rate $(\mathrm{N}=\mathbf{2 1 9 4})$}

(\% of patients with at least one such adenoma-multiple responses per patient are possible)

- LGIN adenoma

- HGIN adenoma

- SSA/P

- Right-sided adenoma

- Flat adenoma
$47,6 \%(1045 / 2194)$

$2.8 \%(62 / 2194)$

$2.9 \%(64 / 1998 * * *)$

$50.0 \%(1097 / 2194)$

$26.5 \%(582 / 2194)$

\section{Adenoma features ( $N=2401$ adenomas)}

Adenoma size ( $\mathrm{mm})$

$1-5 \mathrm{~mm}$

$76.6 \% \quad(N=1839)$

6-9 $\mathrm{mm}$

$14.8 \% \quad(N=355)$

$\geq 10 \mathrm{~mm}$

$8.6 \% \quad(N=207)$

\section{Adenoma histology}

Adenoma, LGIN

$92.8 \% \quad(\mathrm{~N}=2229)$

Adenoma, HGIN

$3.2 \% \quad(N=77)$

SSA/P*

$4.5 \% * \quad(N=95)$

\section{Adenoma location}

Left side

$41.2 \% \quad(\mathrm{~N}=989)$

Right side

$58.8 \% \quad(N=1412)$

\section{Adenoma morphology}

Flat

$28.7 \% \quad(\mathrm{~N}=690)$

Sessile

$62.1 \% \quad(N=1491)$

Pedunculated

$8.9 \% \quad(N=214)$

Depressed

$0.2 \% \quad(\mathrm{~N}=6)$

Abbreviations: LGIN low grade intraepithelial neoplasia, HGIN high grade intraepithelial neoplasia, SSA/P serrated adenomas/polyps, sm submucosal infiltration 
* overall patient numbers with two completed tandem colonoscopies (see Figure 1); in 32 cases no polyp histology was available- subtracting these cases would lead to slightly different figures, e.g. overall ADR 50.55\% (1093/2162)

** see Figure 2

*** SSA/P are separately analyzed in only 6 papers, therefore total $\mathrm{n}$ of adenomas=1998 instead of 2401 
Table 4: OR of missed lesions in relation to colonic location and other factors; reference values for parameters are given in brackets (=ref.). This analysis is based on 1092 patients with 2395 adenomas (due to small group size of depressed form, 6 adenomas were excluded from the analysis sample).

\section{Results model}

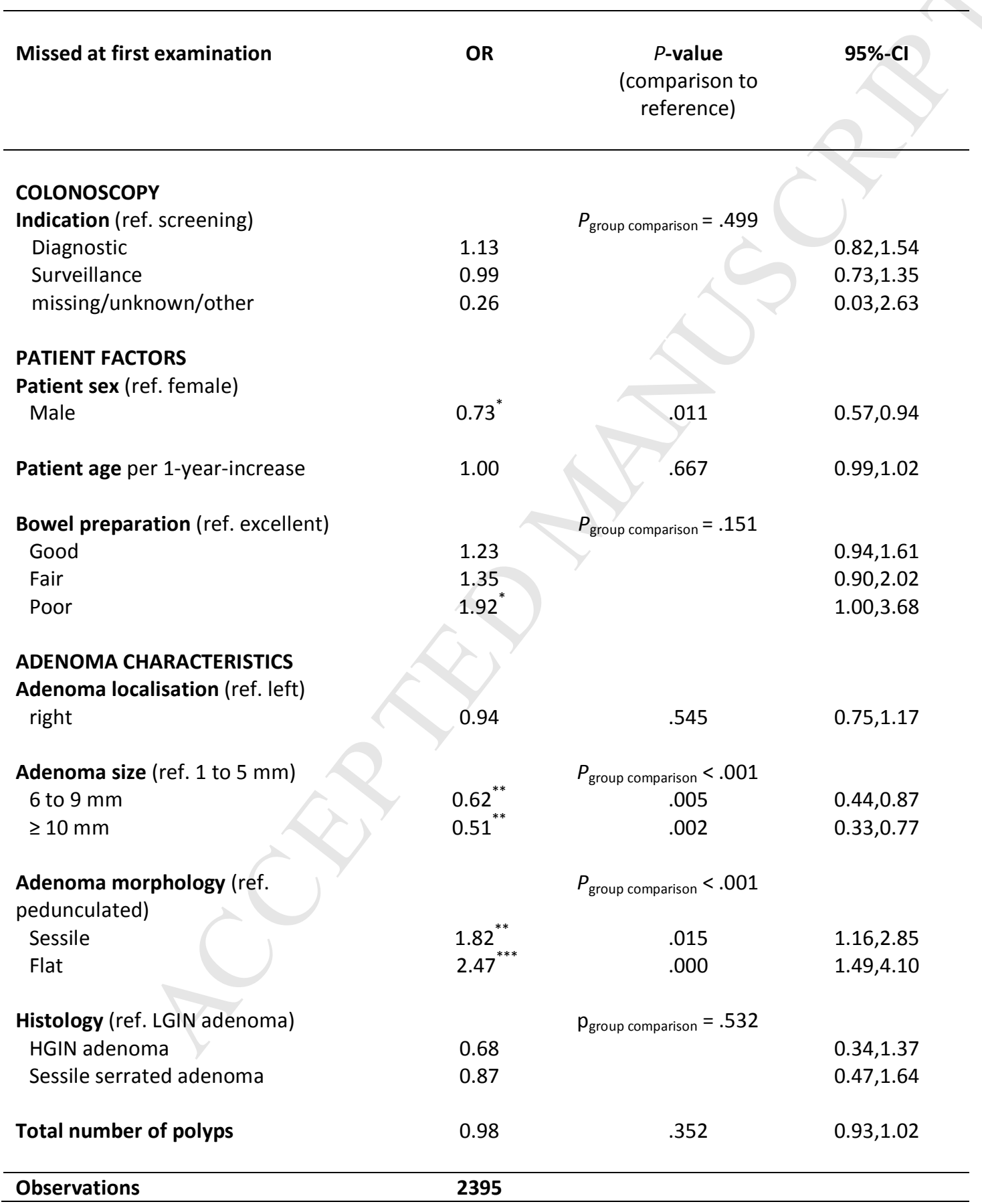

Analysis sample 2395 adenomas in 1092 patients ( 6 cases of depressed adenomas were excluded because of collinearity) 
Exponentiated coefficients

${ }^{*} P<.05,{ }^{* *} P<.01,{ }^{* * *} P<.001$ 
$\mathrm{N}=2218$ all cases

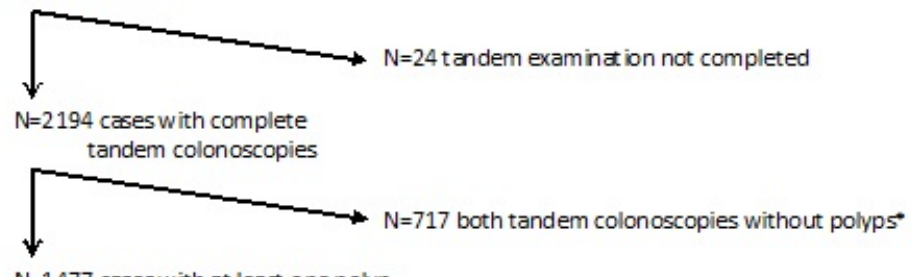

$\mathrm{N}=1477$ cases with at least one polyp

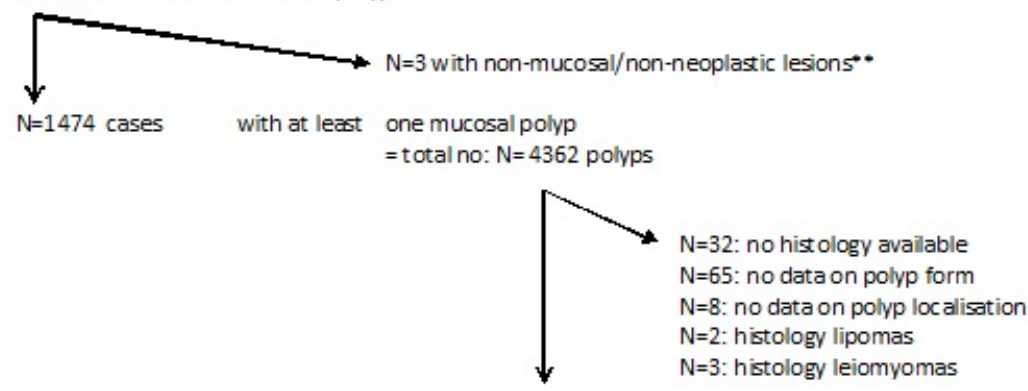

$\mathrm{N}=1454$ cases with $\quad \mathrm{N}=4259=$ mucosal polyps with all data

1851 : hyperplastic polyps

$\mathrm{N}=2$ : submucosal cancer

$\mathrm{N}=5$ : invasive cancer non-specified

$\mathrm{N}=1093$ cases with

$\mathrm{N}=2401$ : mucosal polyps with adenoma histology

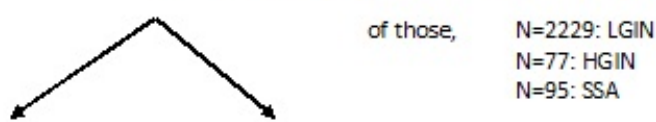

$\mathrm{N}=17521^{\text {st }}$ pass in 908 cases

$N=1613: \operatorname{LGIN}(72,4 \%)$

$\mathrm{N}=65: \quad \operatorname{HGIN}(84,4)$

$\mathrm{N}=75$ : $\quad$ SSA/P $(77,9 \%)$
$N=6492^{\text {nd }}$ pass $(27,03 \%)$

in 447 cases

$\mathrm{N}=616$ : LGIN $(27,6 \%)$

$\mathrm{N}=12: \quad \operatorname{HGIN}(15,6 \%)$

$N=21: \quad \operatorname{SSA} / \mathrm{P}(22,1 \%)$

Abbreviotions: LGIN =low grade intraepithelial neoplasia (low grade ad en oma), HGIN=high grade intraepithelial neoplasia (high grade adenoma), 5sA=sessile serrated adenoma

* including 3 cases with rectal polyps classified as hyperplastic without biopsy

** leiomyoma, lipoma, mucosal ischemia 


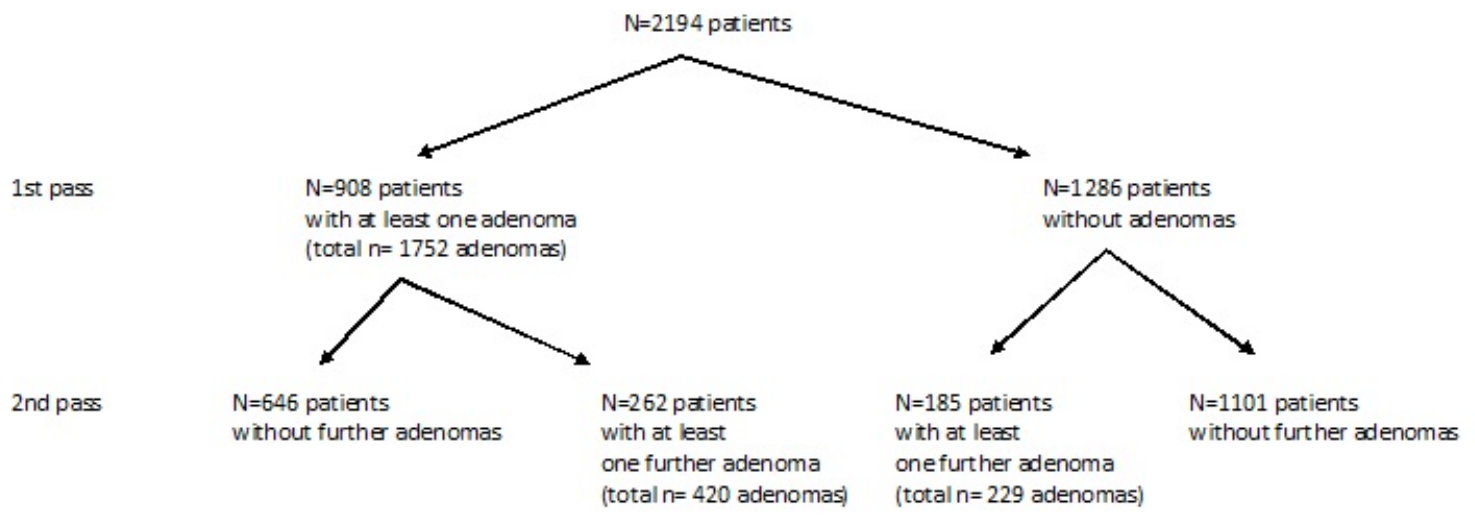




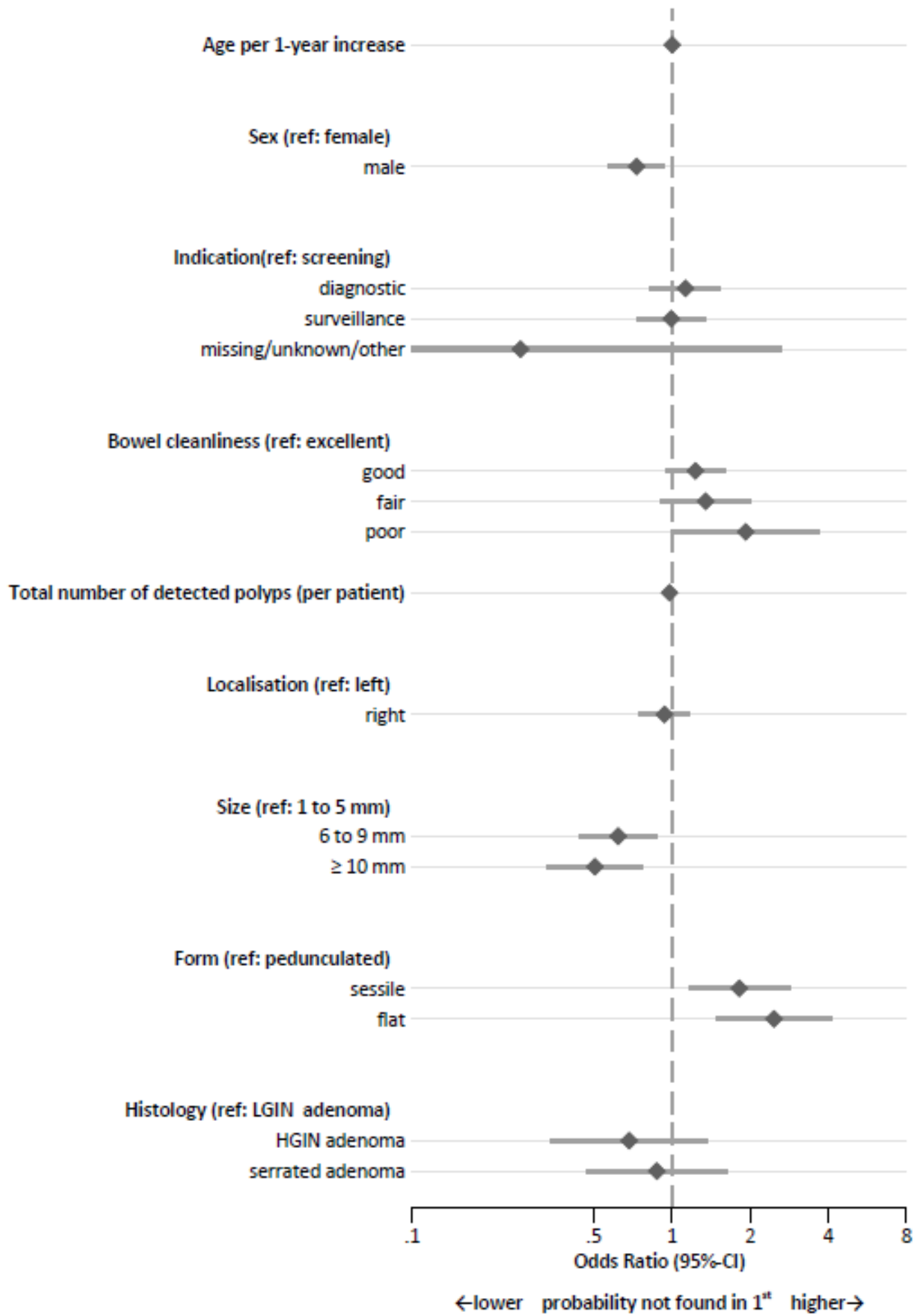




\section{SUPPLEMENTARY MATERIAL ONLINE}

Figure 1 online: Meta analysis of randomized tandem studies fulfilling our inclusion criteria (see Methods p.3 and 4) and being published from 2015 until now (papers from ref. 38-44); mean age in this analysis was 62 years, $61.4 \%$ were male.

\begin{tabular}{|c|c|c|c|c|}
\hline Study & $\begin{array}{l}\text { Right c } \\
\text { Missed }\end{array}$ & $\begin{array}{l}\text { olon } \\
\text { Total }\end{array}$ & $\begin{array}{l}\text { Left } \\
\text { Missed }\end{array}$ & $\begin{array}{l}\text { colon } \\
\text { Total }\end{array}$ \\
\hline Hassan 2018 & 46 & 183 & 38 & 227 \\
\hline Anderson 2018 & 56 & 203 & 33 & 102 \\
\hline Triantafyllou 2017 & 19 & 84 & 30 & 111 \\
\hline Papanikolaou 2017 & 24 & 81 & 11 & 72 \\
\hline Kumar 2017 & 56 & 164 & 17 & 43 \\
\hline Halpern 2015 & 11 & 45 & 9 & 33 \\
\hline Gilani 2015 & 36 & 181 & 12 & 103 \\
\hline $\begin{array}{l}\text { Fixed effect model } \\
\text { Random effects model } \\
\text { Heterogeneity: } I^{2}=51 \%, \tau^{2}\end{array}$ & $\begin{array}{r}248 \\
2=0.0646\end{array}$ & 941 & 150 & 691 \\
\hline
\end{tabular}

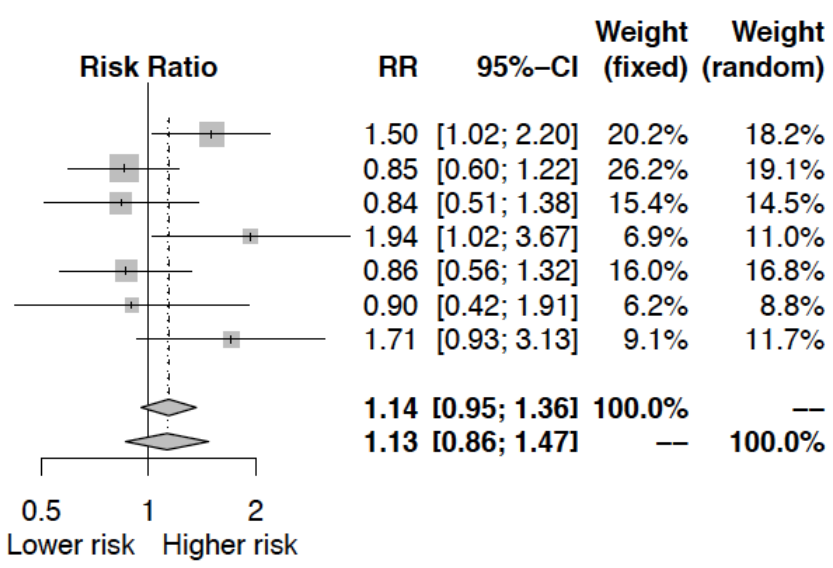


Table 1 online: Results of 6/8 studies in which SSA/P were analyzed separately: OR of missed lesions in relation to colonic location and other factors; reference values or parameters are given in brackets (ref.). This analysis is based on 990 patients with 2112 adenomas

\section{Results model}

\begin{tabular}{|c|c|c|c|}
\hline Missed at first examination & OR & $\begin{array}{l}\text { p-value } \\
\text { (comparison to } \\
\text { reference) }\end{array}$ & $95 \%-\mathrm{Cl}$ \\
\hline Indication (ref. screening) & & $p_{\text {group comparison }}=0.863$ & \\
\hline Diagnostic & 1.14 & 0.467 & $0.82,1.54$ \\
\hline Surveillance & 1.00 & 0.992 & $0.73,1.35$ \\
\hline missing/unknown/other & 1.00 & & \\
\hline \multicolumn{4}{|l|}{ Patient sex (ref. female) } \\
\hline Male & $0.75^{*}$ & 0.040 & $0.56,0.99$ \\
\hline Patient age per 1-year-increase & 1.00 & 0.840 & $0.99,1.01$ \\
\hline Bowel preparation (ref. excellent) & & $p_{\text {group comparison }}=0.530$ & \\
\hline Good & 1.26 & 0.128 & $0.93,1.71$ \\
\hline Fair & 1.44 & 0.096 & $0.94,2.21$ \\
\hline Poor & $2.02^{*}$ & 0.091 & $0.98,4.58$ \\
\hline \multicolumn{4}{|l|}{ Adenoma localisation (ref. left) } \\
\hline right & 1.08 & 0.555 & $0.84,1.37$ \\
\hline Adenoma size (ref. 1 to $5 \mathrm{~mm}$ ) & & $\mathrm{p}_{\text {group comparison }}<0.001$ & \\
\hline 6 to $9 \mathrm{~mm}$ & $0.63^{* *}$ & 0.013 & $0.43,0.91$ \\
\hline$\geq 10 \mathrm{~mm}$ & $0.53^{* *}$ & 0.007 & $0.34,0.84$ \\
\hline Adenoma form (ref. pedunculated) & & $\mathrm{p}_{\text {group comparison }}<0.001$ & \\
\hline Sessile & $1.97^{* *}$ & 0.007 & $1.21,3.20$ \\
\hline Flat & $2.50^{* * *}$ & 0.001 & $1.42,4.40$ \\
\hline Histology (ref. LGIN adenoma) & & $\mathrm{p}_{\text {group comparison }}=0.532$ & \\
\hline HGIN adenoma & 0.73 & 0.400 & $0.35,1.51$ \\
\hline Sessile serrated adenoma & 0.88 & 0.695 & $0.45,1.70$ \\
\hline Total number of polyps & 0.97 & 0.314 & $0.92,1.03$ \\
\hline Observations & 12 & & \\
\hline
\end{tabular}

Analysis sample 2112 adenomas within 990 cases (see Table 3). Exponentiated coefficients. ${ }^{*} p<0.05,{ }^{* *} p<0.01$, ${ }^{* * *} p<0.001$ 
Table 2 online: OR of instrument characteristics for missed adenomas which were part of the multivariate analysis but which are not shown in Table 3 (reference is two white light examination for both passes, i.e. WSL followed by WL)

\begin{tabular}{llcc}
\hline Instrument order (ref. WL->WL) & \multicolumn{3}{c}{ p $_{\text {group comparison }}<0.001$} \\
\hline WL->NBI/FICE & $2.79^{* * *}$ & $<0.001$ & $1.83,4.27$ \\
WL->TER/full spectrum & $2.17^{* *}$ & 0.004 & $1.28,3.67$ \\
WL->EndoRings/Cap & $2.35^{* *}$ & 0.002 & $1.38,4.01$ \\
NBI/FICE->WL & 0.92 & 0.704 & $0.60,1.41$ \\
NBI/FICE->NBI/FICE & 0.95 & 0.837 & $0.55,1.61$ \\
TER/full spectrum->WL & 0.68 & 0.182 & $0.39,1.20$ \\
EndoRings/Cap->WL & 0.73 & 0.317 & $0.40,1.35$ \\
& & & \\
\hline
\end{tabular}

